\title{
Rootstock-induced molecular responses associated with drought tolerance in sweet orange as revealed by RNA-Seq
}

\author{
Luana P. Gonçalves ${ }^{1}$, Raquel L. Boscariol Camargo ${ }^{2}$, Marco Aurélio Takita ${ }^{2}$, Marcos A. Machado²,
}

Walter S. dos Soares Filho ${ }^{3}$ and Marcio G. C. Costa ${ }^{1 *}$ (D)

\begin{abstract}
Background: Citrus plants are commercially propagated by grafting, with the rootstock variety influencing a number of horticultural traits, including drought tolerance. Among the different rootstock varieties available for citrus propagation, 'Rangpur' lime is known to confer enhanced tolerance to drought as compared to other citrus rootstocks. The objective of this study was to investigate the poorly understood molecular responses underlying the rootstock-induced drought tolerance in sweet orange.

Results: RNA-Seq transcriptome analysis was carried out in leaves of sweet orange grafted on 'Rangpur' lime subjected to control and drought-stress treatments, under greenhouse conditions, using the lllumina HiSeq platform. A total of 41,827 unique transcripts were identified, among which 1764 transcripts showed significant variation $(P \leq 0.001)$ between the treatments, with 1081 genes induced and 683 repressed by drought-stress treatment. The transcripts were distributed in 44 different categories of cellular component, molecular function and biological process. Several genes related to cell metabolism, including those involved in the metabolisms of cell wall, carbohydrates and antioxidants, light reactions, biotic and abiotic stress responses, as well as genes coding for transcription factors (TFs), protein kinases (PKs) and proteins involved in the abscisic acid (ABA) and ethylene signaling pathways, were differentially regulated by drought stress. RNA-Seq data were validated by quantitative real-time PCR (qPCR) analysis and comparative analysis of expression of the selected genes between sweet orange grafted on drought-tolerant and -sensitive rootstocks revealed new candidate genes for drought tolerance in citrus.
\end{abstract}

Conclusions: In conclusion, our results showed that only a relatively small but functionally diverse fraction of the sweet orange transcriptome, with functions in metabolism, cellular responses and regulation, was differentially regulated by drought stress. The data suggest that the rootstock-induced drought tolerance in sweet orange includes the transcriptional activation of genes related to the cell wall, soluble carbohydrate and antioxidant metabolisms, biotic and abiotic stress responses, TFs, PKs and ABA signaling pathway, and the downregulation of genes involved in the starch metabolism, light reactions and ethylene signaling. Future efforts to elucidate their functional roles and explore their potential in the citrus genetic improvement should benefit from this data.

Keywords: Citrus, Transcriptome, Water deficit, Abiotic stress

\footnotetext{
* Correspondence: marciogc.costa@gmail.com; proteoma@uesc.br

${ }^{1}$ Centro de Biotecnologia e Genética, Departamento de Ciências Biológicas,

Universidade Estadual de Santa Cruz, Ilhéus, BA 45662-900, Brazil

Full list of author information is available at the end of the article
}

(c) The Author(s). 2019 Open Access This article is distributed under the terms of the Creative Commons Attribution 4.0 International License (http://creativecommons.org/licenses/by/4.0/), which permits unrestricted use, distribution, and reproduction in any medium, provided you give appropriate credit to the original author(s) and the source, provide a link to the Creative Commons license, and indicate if changes were made. The Creative Commons Public Domain Dedication waiver (http://creativecommons.org/publicdomain/zero/1.0/) applies to the data made available in this article, unless otherwise stated. 


\section{Background}

Citrus are the most economically important fruit crops in the world, with sweet orange accounting for nearly $60 \%$ of the total citrus production [1]. Citrus cultivation is limited to tropical and subtropical regions of the world, where drought is one of the major environmental constraints limiting its production [2]. Such a constraint is expected to increase in intensity, frequency, and geographic extent as a result of global climate change. Therefore, understanding the physiological mechanisms of drought tolerance, as well as the correlated molecular responses and associated genes, is an urgent and demanding issue for the adaptation of citrus crops to the present and future climate.

Studies on plant-water relations showed that plants have evolved two major mechanisms of drought resistance: stress avoidance and tolerance. Stress avoidance refers to the ability of the plants to maintain a suitable water status in their tissues under progressive soil water deficit. Avoidance responses rely on different strategies that restrict further water loss, including stomatal closure, reduced leaf area and growth, deep rooting and increased water use efficiency (WUE) [3]. Conversely, stress tolerance refers to the plant's ability to partially dehydrate but remain viable and grow again when rainfall resumes. The primary strategies that contribute to drought tolerance include changes in tissue elasticity (e.g. bulk elastic modulus, $\varepsilon$ ), osmotic adjustment and efficient antioxidant capacity [4].

Various experimental evidences have shown that drought tolerance in Citrus spp., related genera (e.g. Poncirus) and their hybrids (e.g. citranges and citrumelos) is based mainly on avoidance mechanisms that include stomatal closure, and hence decreased transpiration and $\mathrm{CO}_{2}$ assimilation [5-9], reduced leaf area, vegetative growth and yield [1012]. On the other hand, some evidences suggest that citrus plants also exhibit some tolerance mechanisms to drought, such as osmotic [5, 7] and cell wall elastic [13] adjustments. Another striking feature observed in citrus under field conditions is that drought tolerance is a characteristic usually conferred by the rootstock $[14,15]$. For instance, the rootstock 'Rangpur' lime is known to confer enhanced drought tolerance to sweet orange scions under field conditions as compared with other citrus rootstocks, such as 'Swingle' citrumelo, 'Sunki' mandarin, 'Cleopatra' mandarin and Poncirus trifoliata [16]. For this reason, it remains the most preferred rootstock used in the Brazilian citrus industry, despite of its susceptibility to economically important diseases such as citrus blight and citrus sudden death [17]. The outstanding performance of 'Rangpur' has been related to its high root hydraulic conductivity [18], enhanced root growth [19] and remobilization of carbohydrate reserves to the roots [9] under drought-stress conditions.

The response of citrus to drought stress is poorly understood at molecular level. In a first attempt, expressed-sequence-tag
(EST) analysis of 4130 valid reads from roots of 'Rangpur' seedlings cultivated in hydroponic conditions with and without drought stress using polyethylene glycol-6000 (PEG-6000) resulted in the identification of 40 differentially expressed genes [20]. These included homologues to well known genes involved in drought-stress response, such as aquaporins, chaperones, dehydrin, proteases, sucrose synthase and proline-related synthase, as well as homologues to other previously unrelated genes involved with cell energy [e.g. glyceraldehyde-3-phosphate dehydrogenase (GAP3C), phosphoenol pyruvate carboxykinase (PEPCK), glycogenin glucosyltransferase (GGT)], protein synthesis (e.g. ribosomal proteins) and cellular transport (e.g. nodulin-like protein). In another study, a citrus cDNA microarray of $\sim 6000$ genes was used to identify, within 5-24h after transplantation from wet sand to dry sand, 289 drought-induced and 91 drought-repressed genes in roots and 573 drought-induced and 488 drought-repressed genes in leaves of 'Clemenules' mandarin (C. clementina cv. Clementina) grafted on 'Cleopatra' mandarin (C. reshni Hort. ex Tan.) [21]. The products of the stress-inducible genes identified also included well known proteins associated with stress response, such as those involved in the lysine catabolism, proline and raffinose synthesis, hydrogen peroxide reduction, vacuolar malate transport, rare-cold-inducible 2 (RCI2) proteolipids and cell protection (e.g. osmotin, dehydrins and heat-shock proteins). Novel drought-inducible genes were also identified in this study, including those encoding miraculin, $\beta$-carotene hydroxylase, oleoyl desaturase, small subunit ribosomal protein S13A (RPS13A) and constitutive triple response 1 (CTR1) protein kinase. These previous studies not only reinforced the earlier findings about the commonly represented classes of genes induced by drought stress in different plant species, but also suggested that the molecular responses of citrus plants to drought stress may also include the induction of new genes with functions in cell energy, synthesis of proteins, zeaxanthin and linolenoyls, inhibition of proteases and ethylene signaling.

More recently, we have unveiled some functional leaf traits favoring drought tolerance in sweet orange as induced by citrus rootstocks of contrasting drought response [22]. In contrast to plants grafted onto the drought-sensitive rootstock 'Flying Dragon' trifoliate orange ( $P$. trifoliata L. Raf.), those grafted onto the drought-tolerant rootstock 'Rangpur' exhibited a decreased bulk elastic modulus $(\varepsilon)$, low relative water content at turgor loss point $\left(\mathrm{RWC} \mathrm{C}^{\mathrm{TLP}}\right)$ and efficient antioxidant capacity [22]. The molecular basis of these adaptive responses of drought tolerance remains to be elucidated. Our hypothesis is that the drought-tolerant rootstock, but not the drought-sensitive one, induces key components of regulatory networks (e.g. transcription factors, protein kinases and protein phosphatases) controlling the expression of genes involved in cell wall synthesis and modification, osmolyte biosynthesis, antioxidant 
metabolism, among other processes. This hypothesis is supported by evidences that grafting can determine stock-specific transcript (mRNAs and miRNAs) concentration changes in scions, as recently shown in grapevine [23, 24], cucumber and pumpkin [25].

To advance our understanding on the molecular responses underlying the rootstock-induced drought tolerance in sweet orange, we report here, for the first time, the results of an RNA sequencing (RNA-Seq) transcriptome analysis using Illumina deep sequencing of RNA populations obtained from control and drought-stressed leaves of 'Rangpur'-grafted sweet orange collected in our previous study [22]. Quantitative Real-Time-PCR (qPCR) validation of the differentially expressed transcripts from RNA-Seq and their comparative abundance with the "Flying Dragon'-grafted sweet orange revealed novel candidate genes associated with drought-stress tolerance in citrus.

\section{Results}

RNA sequencing and differential gene expression analysis A total of three RNA libraries from leaf samples of control (irrigated; LC1) and drought-stressed (LC3 and LC4) 'Rangpur'-grafted sweet orange were sequenced as $100 \mathrm{bp}$ paired-end runs on an Illumina HiSeq platform. The libraries produced from 5.98 (LC1) to 6.74 (LC3) Gb raw data from paired-end (PE) reads, with a single read length of $101 \mathrm{bp}$, a Q20 percentage (percentage of sequences with sequencing error rate lower than $1 \%$ ) over $96 \%$ and an unknown base percentage $(\mathrm{N})$ of $0.005 \%$ (Additional file 1: Table S1). These data showed that the throughput and sequencing quality were high enough for further analysis.

The reads were aligned with the Citrus sinensis reference genome and the expression levels of a total of 41,827 unique transcripts were quantified based on the Cuffdiff analysis. A total of 1764 transcripts showed significant $(P \leq 0.001)$ variation $(\geq+2.0$ or $\leq-2.0$ fold-change) of expression between the control and drought-stress treatments, with 1081 genes induced and 683 repressed by drought stress (Additional file 2: Table S2-1 and Additional file 3: Table S2-2).

The differentially expressed genes were categorized using Gene Ontology (GO). Based on their similarity, the transcripts were distributed into 44 different categories of cellular component, molecular function and biological process (Fig. 1). In terms of cellular components, drought stress primarily affected cell part and organelle part. The molecular functions of differentially expressed genes (DEGs) were most related to binding and catalytic. Among biological processes, cellular process, metabolic process, biological regulation and response to stimulus contained the most DEGs.

Views of the functional groups that were significantly regulated by drought stress were generated using the MapMan 3.5.1R2 software [26]. These included several genes related to metabolism, cellular response, regulation and receptor-like kinases (Fig. 2 and Additional files 4, 5, 6, 7: Tables S3, S4, S5, S6).

The accuracy of the RNA-Seq expression profiles was further validated by qPCR analysis. Fifteen genes encoding cell wall-related proteins, transcription factors (TFs) and protein kinases (PKs) were selected to validate their expression (Table 1$)$. There was a significant $(P=0.0048)$ positive correlation (Pearson coefficient of 0.75 ) in the expression profiles between RNA-seq and qPCR data, indicating the reliability of the RNA-Seq data.

\section{DEGs related to the cell wall metabolism}

Thirty-two DEGs putatively involved in the cell wall metabolism were identified in the present study, including those encoding for cell wall precursors (e.g. UDP-glucose) and proteins involved in cellulose synthesis (e.g. cellulose synthases - CESAs), cell wall biogenesis (e.g. arabinogalactans and galactosyltransferases) and modification (e.g. expansins, pectinesterases and their inhibitors, polygalacturonase and pectin lyases) (Table 2).

To advance in their validation as candidate genes for drought tolerance in citrus, some of these DEGs were selected for further comparative expression analysis between sweet orange plants grafted on the drought-tolerant 'Rangpur' lime and -sensitive 'Flying Dragon' trifoliate orange. Most of the cell wall-related DEGs analyzed showed significantly higher expression levels in drought-stressed sweet orange grafted on the drought-tolerant ('Rangpur') than on the drought-sensitive ('Flying Dragon') rootstock (Table 3). These include DEGs coding for expansin-like B1 (EXLB1), polygalacturonase (PG), arabinogalactan protein 1 (AGP1), pectinesterase inhibitor 6-like (PEI 6-like), proline-rich protein 4 (PRP4), PEI 54-like, $\beta$-xylosidase 1 (BXL1) and pectin lyase-1 like (PLL1).

\section{DEGs related to other physiological and molecular responses of drought tolerance in citrus}

We have found several DEGs related to other physiological and molecular responses of drought tolerance previously reported in citrus. These include DEGs coding for enzymes involved in the metabolisms of carbohydrates [beta-fructosidase 3 (BFRUCT3), sucrose phosphate synthase 1F (SPS1F), sucrose synthase 3 and 4 (SUS3 and SUS4), hexokinase 2 (HXK2), ADP-glucose pyrophosphorylases 1 and 3 (APS1 and APL3), granule bound starch synthase 1 (GBSS1) and beta-amylase 3 (BAM3)], antioxidants [superoxide dismutase (SOD) and ascorbate peroxidase (APX)], carotenoids [chloroplast beta-carotene hydroxylase (CHY1)] and light reactions (PSBA, PSBO, PSBP and CAB) (Fig. 2a and Additional file 4: Table S3). They also include DEGs related to biotic and abiotic stress response [heat shock proteins (HSPs), early responsive to 


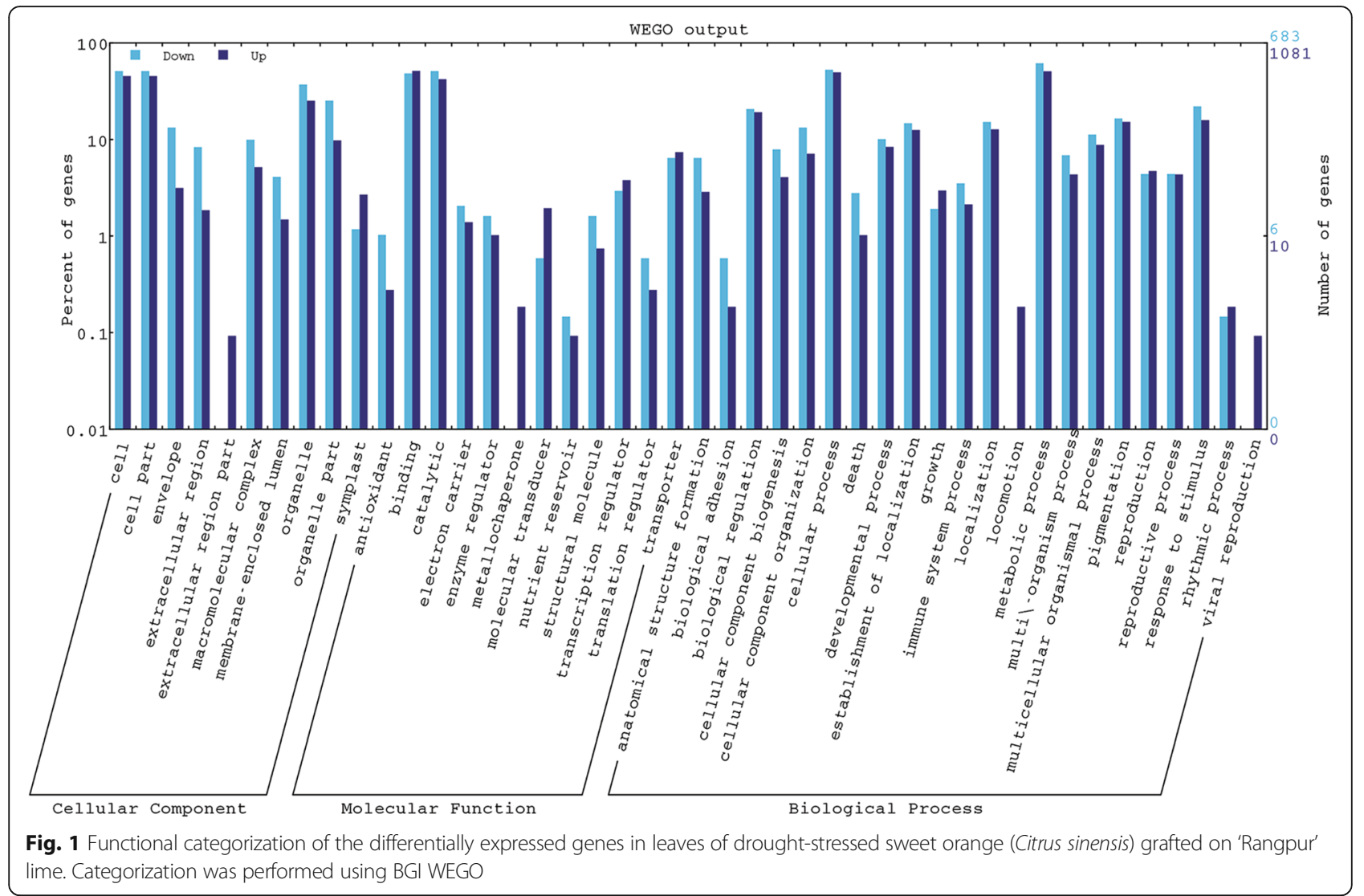

dehydration (ERD), putrescine N-methyltransferases (PMTs) and miraculin] (Fig. 2b and Additional file 5: Table S4) and hormone signaling (HVA22, MARD1, AREB2, PP2Cs, PYR/PYL/RCAR and ERT2) (Fig. 2c and Additional file 6: Table S5).

\section{DEGs related to transcription factors (TFs)}

We have found 120 DEGs coding for TFs, distributed in several large TF families, including MYB, AP2/ERF, WRKY, bZIP, NAC, zinc finger (ZF) and basic helix-loop-helix (bHLH), among others (Fig. 2c; Table 4; Additional file 7: Table S6). ZF and MYB were the TF families with the largest number of DEGs, 23 and 18 genes, respectively (Table 4). Most DEGs in the different TF families were upregulated by drought stress, except for those belonging to the auxin response factor (ARF) and homeobox (HB) families, in which most of the DEGs were downregulated by drought stress (Table 4).

Three of the most upregulated TF DEGs found in the present study (BEE 3-LIKE, WRKY4O and NAC2) were selected for further expression validation (Table 1) and comparative expression analysis between sweet orange plants grafted on the drought-tolerant ('Rangpur') and -sensitive ('Flying Dragon') rootstocks (Table 3). qPCR analysis confirmed all of them as highly induced $T F$ genes by drought stress in sweet orange grafted on 'Rangpur' (Table 1). On the other hand, no significant changes in the level of expression of these TFs were observed in drought-stressed sweet orange grafted on 'Flying Dragon' (Table 3).

\section{DEGs related to protein kinases (PKs)}

Ninety DEGs coding for PKs distributed in several families were identified in the present study (Fig. 2d; Table 4; Additional file 7: Table S6). The largest number of DEGs was found in the leucine rich repeat (LRR) and Serine/ Threonine-protein kinase (STK) families, with 46 and 10 genes, respectively (Table 4). As also observed for TF DEGs, most DEGs coding for PKs were upregulated by drought stress, except for those of LRR and Cdc2-related protein kinase families, whose most DEGs were downregulated by drought stress (Table 4).

Three PKs coding for wall associated kinases (WAKs) were chosen in the present study for validation of expression, given their putative involvement in cell wall signaling pathways. qPCR analysis confirmed a significant induction by drought stress for only one of them, WAKL2, whereas the other WAKs (WAKL8 and WAK2) were downregulated by drought (Table 1). Comparative expression analysis between sweet orange grafted on the drought-tolerant ('Rangpur') and -sensitive ('Flying Dragon') rootstocks showed that all WAKs analyzed were differentially regulated by drought according to the rootstock (Table 3). WAKL2 was upregulated in the 


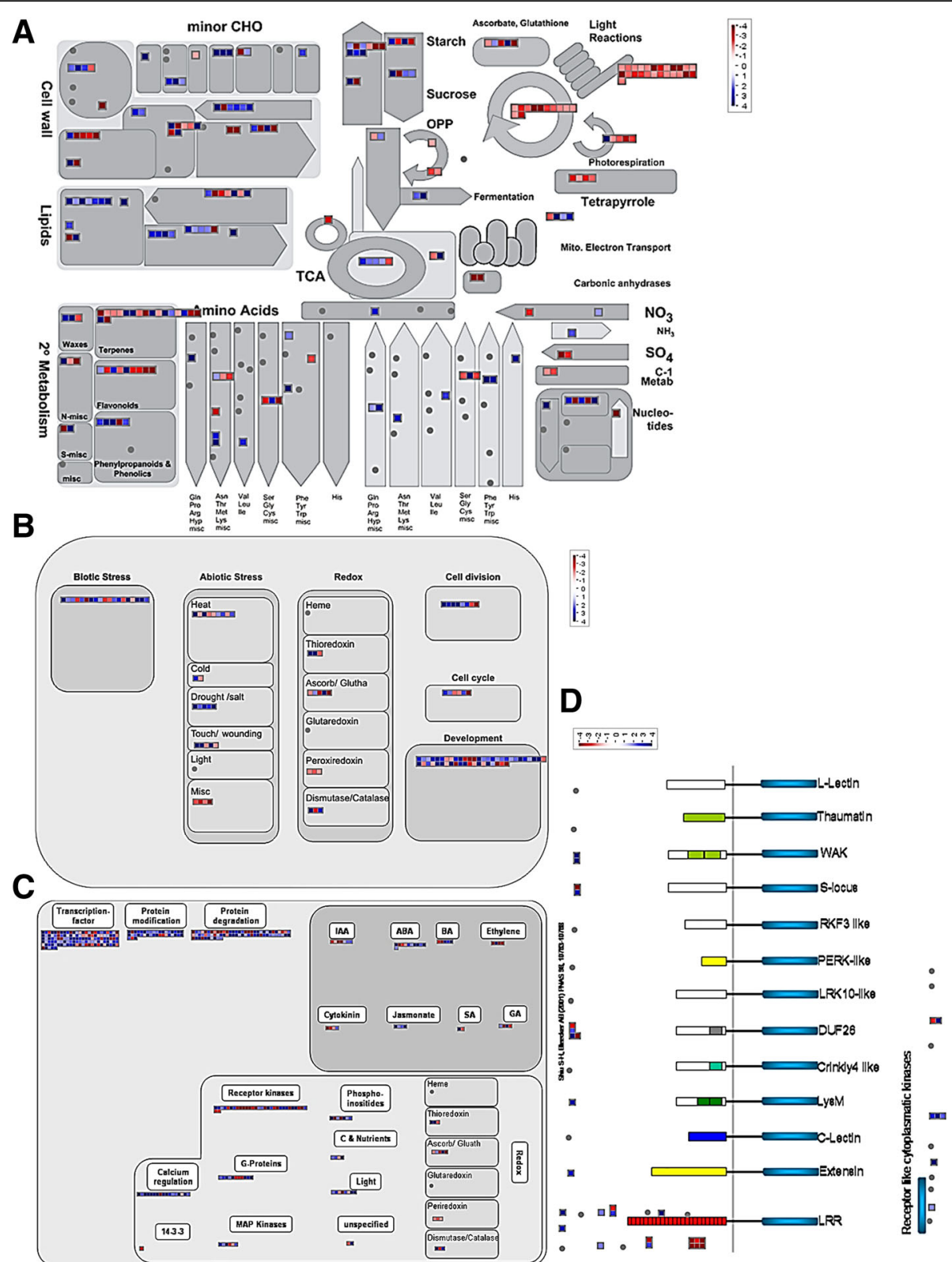

Fig. 2 Overview of the differentially expressed genes related to metabolic pathways (a), cellular responses (b), regulation (c) and receptor-like kinases (d) in leaves of drought-stressed sweet orange (Citrus sinensis) grafted on 'Rangpur' lime. Genes that were significantly induced are shown in blue and repressed genes shown in red. Abbreviations/definitions: LRR, leucine-rich repeats; Extensin, RLK with extensin motif; LysM, RLKs with lysine motif; C-lectin, RLKs with lectin-like motifs; Crinkly 4-like, RLKs with crinkly4-like domains; DUF26, domain of unknown function 26; LRK 10-like, RLK gene linked to Lr10 locus; L-lectin, RLKs with lectin-binding domains; PERK-like, proline-rich extensin-like kinase; S-locus, RLK with S-domain similar to S-locus glycoproteins; RKF3-like, receptor-like kinase in flowers 3; Thaumatin, RLK-like thaumatin protein; WAK, wall-associated kinase

drought-tolerant, but downregulated in the drought-sensitive rootstock, whereas the opposite was observed for WAKL8. Conversely, WAK2 was downregulated by drought stress in both rootstocks, but at different levels (Table 3).

\section{Discussion}

In this study, drought-responsive genes were identified using Illumina deep sequencing data generated from leaves of droughted sweet orange plants grafted on the drought-tolerant rootstock 'Rangpur' lime. The reliability of our transcriptomic data was supported by detection of 41,827 (94.2\%) unique transcripts out of 44,387 currently known sweet orange transcripts [27], and by the results of qPCR analysis (Table 1 ). They revealed a total of 1764 transcripts showing significant variation of expression in response to the drought stress conditions 
Table 1 Validation of differentially expressed genes related to cell wall metabolism, transcription factors and receptor-like kinases in leaves of drought-stressed sweet orange (Citrus sinensis) grafted on 'Rangpur' lime

\begin{tabular}{llll}
\hline ID citrus & Gene description & RNAseq fold change $(P \leq 0.001)$ & qPCR log fold change* \\
\hline Cell wall metabolism & & 36.764 & 3.716 \\
Orange1.1g025810m & Expansin-Like B1 & 14.367 & 0.539 \\
Orange1.1g013402m & Polygalacturonase (pectinase) & 3.787 & 1.406 \\
Orange1.1g030669m & Arabinogalactan protein 1 & -4.516 & -0.579 \\
Orange1.1g047288m & Pectinesterase inhibitor 6-like & -6.134 & 0.219 \\
Orange1.1g029350m & Proline-Rich Protein 4 & -11.369 & 0.205 \\
Orange1.1g009682m & Pectinesterase inhibitor 54-like & -12.863 & -1.552 \\
Orange1.1g025025m & Expansin A4 & -14.818 & 0.317 \\
Orange1.1g007089m & B-Xylosidade 1 & -77.398 & -2.640 \\
Orange1.1g011204m & Pectin lyase-1 like & & 5.925 \\
Transcription factor & & 12.023 & 3.412 \\
Orange1.1g024111m & bHLH BEE 3-like & 14.04 & 2.673 \\
Orange1.1g025097m & WRKY transcription factor 40 & 10.171 & -2.482 \\
Orange1.1g021910m & NAC transcription factor 2 & & 1.386 \\
Receptor-like kinase & & 7.145 & -0.477 \\
Orange1.1 g031436 & Wall-associated receptor kinase-like 8 & 8.891 & 4.977 \\
Orange1.1 g026214 & Wall-associated receptor kinase-like 2 & & \\
Orange1.1 g041671 & Wall-associated receptor kinase 2 & & \\
\hline
\end{tabular}

${ }^{*} r=0.75(P=0.0048)$

tested, which is far higher than in the previous studies $[20,21]$. Our results show that the fraction of the sweet orange transcriptome regulated by drought stress is relatively small $(4.2 \%)$, mostly represented by upregulated genes $(61.3 \%)$ and functionally diverse (Figs. 1 and 2).

A striking leaf physiological trait of drought tolerance exhibited by sweet orange plants grafted on the drought-tolerant 'Rangpur' lime, but not by those grafted on the drought-sensitive 'Flying Dragon', is their increased cell wall elasticity (decreased $\varepsilon$ ) under drought [22], which contributes to the maintenance of cell turgor or symplast volume. Therefore, DEGs related to the cell wall metabolism are strong candidate genes for drought tolerance in citrus. In fact, 32 DEGs putatively involved in the cell wall metabolism were identified by RNA-Seq analysis (Table 2), with most of them showing significantly higher expression levels in the drought-tolerant ('Rangpur') than in the droughtsensitive ('Flying Dragon') rootstock (Table 3). These include DEGs coding for expansins (EXPs), PGs, PEIs, BXLs and PLLs, which are cell wall modifying proteins that modulate cell wall extensibility (EXPs, PEIs and BXLs) or plasticity/rheology (PGs and PLLs), contributing to the cell wall loosening [28]. They also include DEGs coding for AGPs and PRPs, which are structural cell wall proteins that have been proposed to act as plasticisers to loosen the pectin network or as stabilisers of the cell wall during times of cell stress or expansion [28, 29]. Involvement of these cell-wall related proteins in plant response and tolerance to drought stress has been reported in some previous studies. For instance, the Arabidopsis ortholog of EXLB1 was shown to exhibit an early upregulation in to moderate drought stress, which was interpreted as an important strategy of drought acclimation by cell wall adjustment [30]. A pepper PEI gene (CaPMEI1) was shown to be induced by drought stress and its overexpression has conferred enhanced drought tolerance in transgenic Arabidopsis, as evidenced by their reduced transpiration and enhanced root elongation under drought conditions [31]. The mandarin ortholog of BXL1 was shown to be highly induced by drought stress in roots [21]. Therefore, the differential expression of all these cell wall-related protein-encoding genes in rootstock varieties of contrasting drought tolerance makes them novel candidate genes for drought tolerance in citrus.

Some of the upregulated genes related to the metabolism of carbohydrates encode orthologs BFRUCT3, SPS1F, SUS3 and SUS4 (Additional file 4: Table S3), whose products of their enzymatic activities, glucose and sucrose [32-34], have been shown to increase significantly in leaves of drought-stressed sweet orange grafted on the drought-tolerant 'Rangpur' lime rootstock [35]. These sugars have been shown to play a pivotal role as osmoprotectants, helping to stabilise cellular membranes and to maintain cell turgor, a prerequisite for survival under stress conditions [36]. The downregulation of genes related to starch synthesis and degradation, such as those 
Table 2 Differentially expressed genes related to the cell wall metabolism in leaves of drought-stressed sweet orange (Citrus sinensis) grafted on 'Rangpur' lime

\begin{tabular}{|c|c|c|}
\hline ID Citrus & Gene description & $\log _{2}$ fold change \\
\hline \multicolumn{3}{|l|}{ Cell wall precursors } \\
\hline Orange1.1g007727m & UDP-sugar pyrophosphorylase & 5.581 \\
\hline Orange1.1g001947m & ARA1 (ARABINOSE KINASE 1) & 3.566 \\
\hline Orange1.1g011650m & UDP-glucose 6 & 2.938 \\
\hline Orange1.1g040584m & UDP-glucose 4-epimerase 5 & 2.7 \\
\hline Orange1.1g005949m & UDP-L-rhamnose synthase & 2.664 \\
\hline Orange1.1g019795m & UDP-D-glucose 4-epimerase 1 & -6.302 \\
\hline \multicolumn{3}{|l|}{ Cellulose synthesis } \\
\hline Orange1.1g001382m & Cellulose synthase 6 & 10.771 \\
\hline Orange1.1g001421m & Cellulose synthase 3 & 5.953 \\
\hline Orange1.1g001373m & Cellulose synthase 9 & 4.004 \\
\hline Orange1.1g026442m & Cellulose synthase family protein & -2.207 \\
\hline Orange1.1g009524m & Cellulose synthase-like protein e1-like & -2.554 \\
\hline Orange1.1g006639m & Cellulose synthase family protein & -3.725 \\
\hline Orange1.1g004692m & Cellulose synthase 8 & -4.088 \\
\hline \multicolumn{3}{|l|}{ Cell wall biogenesis } \\
\hline Orange1.1g030669m & AGP1 (Arabinogalactan Protein 1) & 3.787 \\
\hline Orange1.1g009630m & Galactosyltransferase family protein & 3.03 \\
\hline Orange1.1g025959m & FLA13 (Fasciclin-Like Arabinogalactan Protein 13 Precursor) & 2.805 \\
\hline Orange1.1g007197m & Xyloglucan galactosyltransferase katamari1 & 2.539 \\
\hline Orange1.1g031862m & AGP2 (Arabinogalactan Protein 2) & 2.509 \\
\hline Orange1.1g044183m & Fasciclin-like arabinogalactan protein 4-like & -2.618 \\
\hline Orange1.1g029405m & PRP4 (Proline-Rich Protein 4) & -6.134 \\
\hline \multicolumn{3}{|l|}{ Cell wall modification } \\
\hline Orange1.1g025810m & Expansin-like B1 & 36.764 \\
\hline Orange1.1g013402m & Probable Polygalacturonase-like & 14.367 \\
\hline Orange1.1g008722m & Pectin Esterase Inhibitor-like & 3.415 \\
\hline Orange1.1g005706m & Rhamnogalacturonate lyase b-like isoform $\times 2$ & 2.82 \\
\hline Orange1.1g013734m & Protein notum homolog isoform $\times 2$ & -3.309 \\
\hline Orange1.1g018173m & Pectinesterase 3-like & -3.599 \\
\hline Orange1.1g011170m & Alpha-l-fucosidase 1-like & -4.527 \\
\hline Orange1.1g009682m & Probable pectinesterase pectinesterase inhibitor 54-like & -11.369 \\
\hline Orange1.1g025025m & Expansin A 4 & -12.863 \\
\hline Orange1.1g012308m & Pectin lyase-like superfamily protein isoform 1 & -13.862 \\
\hline Orange1.1g007089m & BETA-d-xylosidase family protein & -14.818 \\
\hline Orange1.1g011204m & Pectin lyase-like superfamily protein isoform 1 & -77.398 \\
\hline
\end{tabular}

coding for HXK2, APS1, APL3, GBSS1 and BAM3 [37], is also in agreement with reductions in the starch content previously observed in leaves of sweet orange grafted on 'Rangpur' lime subjected to moderate water deficit [9], which occur probably as a consequence of the low photosynthesis.

Upregulation of genes coding for the antioxidant enzymes SOD and APX, and the carotenoid biosynthesis enzyme CHY1 (Additional file 4: Table S3) correlates with our previous observation that the drought tolerant 'Rangpur' roostock induced an efficient control of oxidative stress, which avoided damages to its photosynthetic apparatus and helped to maintain the cellular homeostasis under drought [22]. The mandarin ortholog of $C H Y 1$ was shown to be induced by drought stress in leaves and roots and characterized as a novel molecular response of 
Table 3 Quantitative Real-Time-PCR (qPCR) expression analysis of some drought-regulated genes in leaves of drought-stressed sweet orange (Citrus sinensis) grafted on 'Rangpur' lime and 'Flying Dragon' trifoliate orange

\begin{tabular}{|c|c|c|c|}
\hline \multirow[t]{2}{*}{ ID citrus } & \multirow[t]{2}{*}{ Gene description } & \multicolumn{2}{|c|}{$\log _{2}$ fold change (drought/control) } \\
\hline & & 'Rangpur' & 'Flying Dragon \\
\hline \multicolumn{4}{|l|}{ Cell wall metabolism } \\
\hline Orange1.1g025810m & Expansin-Like B1 & 3.716 & 0.871 \\
\hline Orange1.1g013402m & Polygalacturonase (pectinase) & 0.539 & -0.636 \\
\hline Orange1.1g030669m & Arabinogalactan protein 1 & 1.406 & -0.277 \\
\hline Orange1.1g047288m & Pectinesterase inhibitor 6-like & -0.579 & -2.101 \\
\hline Orange1.1g029350m & Proline-Rich Protein 4 & 0.219 & -2.826 \\
\hline Orange1.1g009682m & Pectinesterase inhibitor 54-like & 0.205 & -2.439 \\
\hline Orange1.1g025025m & Expansin A4 & -1.552 & 0.272 \\
\hline Orange1.1g007089m & $\beta$-Xylosidase 1 & 0.317 & -1.833 \\
\hline Orange1.1g011204m & Pectin lyase-1 like & -2.640 & -3.699 \\
\hline \multicolumn{4}{|l|}{ Transcription factor } \\
\hline Orange1.1g024111m & bHLH BEE 3-like & 5.925 & 0.600 \\
\hline Orange1.1g025097m & WRKY transcription factor 40 & 3.412 & -0.785 \\
\hline Orange1.1g021910m & NAC transcription factor 2 & 2.673 & 0.945 \\
\hline \multicolumn{4}{|l|}{ Receptor-like kinase } \\
\hline Orange1.1 g031436 & Wall-associated receptor kinase-like 8 & -2.482 & 0.889 \\
\hline Orange1.1 g026214 & Wall-associated receptor kinase-like 2 & 1.386 & -2.195 \\
\hline Orange1.1 g041671 & Wall-associated receptor kinase 2 & -0.477 & -1.276 \\
\hline
\end{tabular}

drought tolerance in citrus [21], since it is involved in the biosynthesis of zeaxanthin, a protective xanthophyll of the photosynthetic apparatus and a major precursor of abscisic acid (ABA).

Downregulation of all genes related to light reactions (Additional file 4: Table S3), such as PSBA, PSBO, PSBP and $C A B$, also corroborates with our previous findings that 'Rangpur' lime induced a decrease in the chlorophyll content in leaves of drought-stressed sweet orange, as indicated by the significant increase in the minimum fluorescence $\left(\mathrm{F}_{0}\right)$ of chlorophyll $a$ under drought conditions [22]. The loss of chlorophyll during periods of drought has been described as an important mechanism for photosynthetic photoprotection in plants, allowing less light absorption [38].

DEGs related to cellular response that were modulated by drought stress included homologues to well known genes involved in both biotic and abiotic stress response and redox regulation, as well as homologues to previously unknown genes associated with cell division, cell cycle and development (Fig. 2b and Additional file 5: Table S4). HSPs, ERDs, PMTs and miraculin are some of the well kwown gene products involved in the stress cellular responses in citrus and other plants [20, 21, 39, 40].

DEGs involved in the hormonal signaling pathways of ABA, auxin, ethylene, jasmonic acid (JA), salicylic acid (SA) and brassinosteroids were also identified (Fig. 2c and Additional file 6: Table S5). The ABA-regulated homologs of HVA22, MARD1, AREB2 and PP2Cs were highly induced by drought stress, whereas a downregulation was observed for ABA DEFICIENT 1/2, CSPYL4 and CsPYL5 (Additional file 6: Table $\mathrm{S} 5$ ). A positive regulation of CsPP2CA genes (e.g. ABI1, ABI2, CsHAB1) concomitantly with the downregulation of $C S P Y R / P Y L / R C A R$ genes (e.g. CSPYL4 and CSPYL5) in response to ABA accumulation during fruit ripening and leaf dehydration has been previously reported in sweet orange [41]. Taken together, our results suggest that these DEGs act as central elements in the signaling pathway and perception of $\mathrm{ABA}$ in citrus. On the other hand, except for a gene coding for the ethylene-responsive nuclear protein (ERT2), all the other genes related to the ethylene signaling pathway were downregulated by drought stress (Additional file 6: Table S5). These results suggest that drought inhibits the ethylene signaling in citrus, as previously reported for mandarin [21].

TFs have been shown to play important roles in drought stress response and tolerance via regulating downstream stress-responsive genes. Therefore, DEGs related to TFs also represent good candidate genes for drought tolerance in citrus. More than one hundred DEGs coding for TFs distributed in the major TF families (e.g. MYB, AP2/ERF, WRKY, bZIP, NAC, ZF, bHLH, HB, ARF and NF-Y) were identified in the present study (Fig. 2c; Additional file 7: Table S6), with most of them showing an upregulated 
Table 4 Number of differentially expressed genes belonging to the different transcription factor and protein kinase gene families in leaves of drought-stressed sweet orange (Citrus sinensis) grafted on 'Rangpur' lime

\begin{tabular}{|c|c|c|}
\hline Gene families & Downregulated & Upregulated \\
\hline \multicolumn{3}{|l|}{ Transcription factor } \\
\hline MYB domain transcription factor family & 6 & 12 \\
\hline WRKY domain transcription factor family & 1 & 5 \\
\hline bZIP transcription factor Family & 1 & 7 \\
\hline HSF, Heat shock transcription & 2 & 1 \\
\hline NAC transcription factor Family & 0 & 7 \\
\hline Trihelix transcription factor & 1 & 3 \\
\hline Zinc finger Family & 7 & 16 \\
\hline ARF, Auxin response factor family & 5 & 4 \\
\hline Aux/IAA Family & 0 & 2 \\
\hline bHLH, Basic helix-loop-helix family & 2 & 6 \\
\hline AP2/EREBP, APETALA2/Ethylene-responsive element binding protein family & 2 & 5 \\
\hline HB, Homeobox transcription factor family & 7 & 1 \\
\hline NF-Y, Nuclear Factor Y family & 1 & 2 \\
\hline \multicolumn{3}{|l|}{ Protein kinase } \\
\hline Leucine Rich Repeat & 26 & 20 \\
\hline Protein tyrosine kinase & 1 & 5 \\
\hline Serine/threonine-protein kinase & 0 & 10 \\
\hline Histidine kinase & 0 & 3 \\
\hline PI3K, Phosphoinositide 3-kinase & 0 & 5 \\
\hline MAP kinase & 1 & 5 \\
\hline Aspartate kinase & 0 & 2 \\
\hline PIP5K, Phosphatidylinositol-4-phosphate 5-Kinase & 0 & 2 \\
\hline Cdc2-related protein kinase & 3 & 1 \\
\hline Wall-associated kinase & 0 & 3 \\
\hline REC, Response regulator receiver domain & 0 & 3 \\
\hline
\end{tabular}

expression in response to drought stress (Table 4). Two downregulated $M Y B$ DEGs found in the present study, EARLY FLOWERING MYB (EFM) and MYB308-LIKE (Additional file 7: Table S6), were previously identified in another study as sweet orange CsMYB129 and CsMYB64, respectively, and shown to be downregulated in callus treated with mannitol [42]. EFM is an important flowering regulator that directly represses FLOWERING LOCUS T (FT) expression in the leaf vasculature [43]. Similarly, one upregulated $b Z I P$ DEG found in the present study, orange1.1g013223m (Additional file 7: Table S6), was previously characterized in $P$. trifoliata and its overexpression in tobacco increased drought tolerance of transgenic plants, possibly by inducing the synthesis of protective compounds, such as polyamines, or proteins, such as LEAs [44]. We also found an upregulated AP2/ERF DEG coding for DREB2A (Additional file 7: Table S6), which has been widely recognized as a key regulator in response to drought and temperature stresses, with high potential to increase plant tolerance to these stresses [45].

BEE 3-LIKE, WRKY4O and NAC2 were the three most upregulated TFs found in the present study (Table 1). Their differential expression between the rootstock varieties of contrasting drought tolerance (Table 3) has rendered them strong candidate genes for drought tolerance in citrus. Previous studies have shown that the Arabidopsis ortholog of BEE 3-LIKE (BRASSINOSTEROID ENHANCED EXPRESSION 3-LIKE) is a brassinosteroid (BR)-induced early response $b H L H$ gene that also is antagonistically regulated by $\mathrm{ABA}$, suggesting that it may function as a signaling intermediate in multiple pathways [46], whereas the hybrid poplar (Populus alba $\times$ P. glandulosa) ortholog of BEE 3-LIKE (PagBEE3L) was shown to induce plant growth and biomass production in transgenic poplar plants by increasing the xylem cell proliferation in stem tissue [47]. The Arabidopsis ortholog of NAC2, ATAF1, was shown to 
enhance the drought tolerance when overexpressed in transgenic Arabidopsis plants via stomatal regulation and induction of stress-responsive genes, such as $A D H 1, R D 29 A$ and COR47 [48]. The Meiwa kumquat (Fortunella crassifolia) ortholog of WRKY4O (FCWRKY4O) was showed to be induced by salt, salicylic acid (SA), cold and ABA, but repressed by dehydration, and its overexpression in tobacco increased the tolerance of the transgenic plants to oxidative stress and the mRNA abundance of genes coding for peroxidase (POD) and catalase (CAT) [49]. The functional roles of the respective sweet orange orthologs of BEE 3-LIKE, WRKY4O and NAC2 remain to be elucidated.

Upstream of TFs, PKs regulate various signal transduction pathways in abiotic stress responses via perception of stress signals and activation of downstream signaling pathways by phosphorylating specific target proteins. Thus, they also represent good candidate genes for drought tolerance in citrus. We have found nearly one hundred DEGs coding for PKs, distributed in several families (Fig. 2d; Additional file 7: Table S6), with most of them also showing an upregulated expression in response to drought stress (Table 4). Two upregulated PKs belonging to the STK (orange1.1g019628m) and MAP kinase (orange1.1g023609m) families (Additional file 7: Table S6) are orthologs of the Arabidopsis SRK2C and MPK6, respectively. SRK2C is a SnRK2 protein involved in ABA signaling that significantly increase drought tolerance by upregulating many stress-responsive genes, such as RD29A, COR15A, and DREB1A/CBF3 [50]. MPK6 was shown to be induced in response to various abiotic and biotic stresses and it is considered a universal regulator in plant stress responses [51]. The differential expression of WAKL8, WAKL2 and WAK2 between rootstocks of contrasting drought tolerance (Table 3) also highlight these WAKs as relevant candidate genes for drought tolerance in citrus. WAK2 binding to native pectins on the cell wall is required for cell expansion during development, while its binding to pectin fragments like oligo-galacturonides (OGs) activates a stress response pathway [52].

\section{Conclusion}

The use of deep sequencing technology allowed to characterize the genome-wide molecular responses associated with the rootstock-induced drought tolerance in sweet orange. This analysis revealed that only a relatively small (4.2\%) but functionally diverse fraction of the sweet orange transcriptome, with functions in metabolism, cellular responses and regulation, showed a significant variation of expression in response to the drought stress conditions tested. Taken together with the comparative expression analysis between sweet orange plants grafted on drought-tolerant and -sensitive rootstocks, as well as with the previously reported physiological and molecular responses of drought tolerance in citrus, the results suggest that drought tolerance in sweet orange involves the transcriptional activation of genes related to the metabolisms of cell wall, soluble carbohydrates and antioxidants and also of well known genes involved in biotic and abiotic stress responses, and the downregulation of genes involved in the starch metabolism, light reactions and ethylene signaling pathway. The regulatory pathways that modulate these downstream responses include several drought-regulated TFs, PKs and ABA signaling proteins. A schematic model depicting the transcriptional responses associated with the rootstock-induced drought tolerance in sweet orange is shown in Fig. 3. The present study provides a useful reference for further exploration of the functions of candidate genes and applications on the genetic improvement of citrus rootstocks.

\section{Methods}

\section{Plant material}

Leaf samples of twelve-month-old sweet orange [Citrus sinensis (L.) Osbeck var. 'Westin'] grafted onto 'Rangpur' lime (Citrus limonia Osbeck, 'Santa Cruz' selection) or 'Flying Dragon' trifoliate orange [Poncirus trifoliata (L.) Raf.], subjected to control and drought stress treatments as previously reported [22], were used in the present study. These plants were obtained from the Citrus Germplasm Bank of Embrapa Cassava \& Fruits (Cruz das Almas, BA, Brazil). The leaf predawn water potentials $\left(\Psi_{\mathrm{w}}\right)$ in the control and drought-stress treatments were maintained at $-0,2-0,5 \mathrm{MPa}$ and $-1,5 \mathrm{MPa}$, respectively. Five leaves (technical replicates) of three plants (biological replicates) were collected from each treatment and immediately frozen in liquid nitrogen.

\section{RNA isolation and RNA-Seq preparation}

Total RNA was isolated from five leaves of each plant with the RNAqueous ${ }^{\ominus}$ kit (Applied Biosystems, Foster City, USA), following the manufacturer's instructions. RNA was sequentially treated with DNase I ( $100 \mathrm{Ug}^{-1}$ total RNA) (FPLC pure, Amersham Pharmacia Biotech, Piscataway, USA), according to the manufacturer's instructions. The quality and integrity of the extracted RNA were evaluated by $1 \%(w / v)$ agarose gel analysis and the concentration measured on a NanoDrop 2000 spectrophotometer (NanoDrop Technologies, Wilmington, DE). One or two replicate RNA extractions were carried out in each plant for the construction of one (LC1) or two (LC3 and LC4) independent replicate cDNA libraries for control and drought treatments, respectively (Additional file 1: Table S1). Each cDNA library contained a pool of RNA in equal proportions from three plants per treatment. The RNA samples were sent to Macrogen Inc. (South Korea) for mRNA purification, cDNA library construction and sequencing using the platform Illumina. 


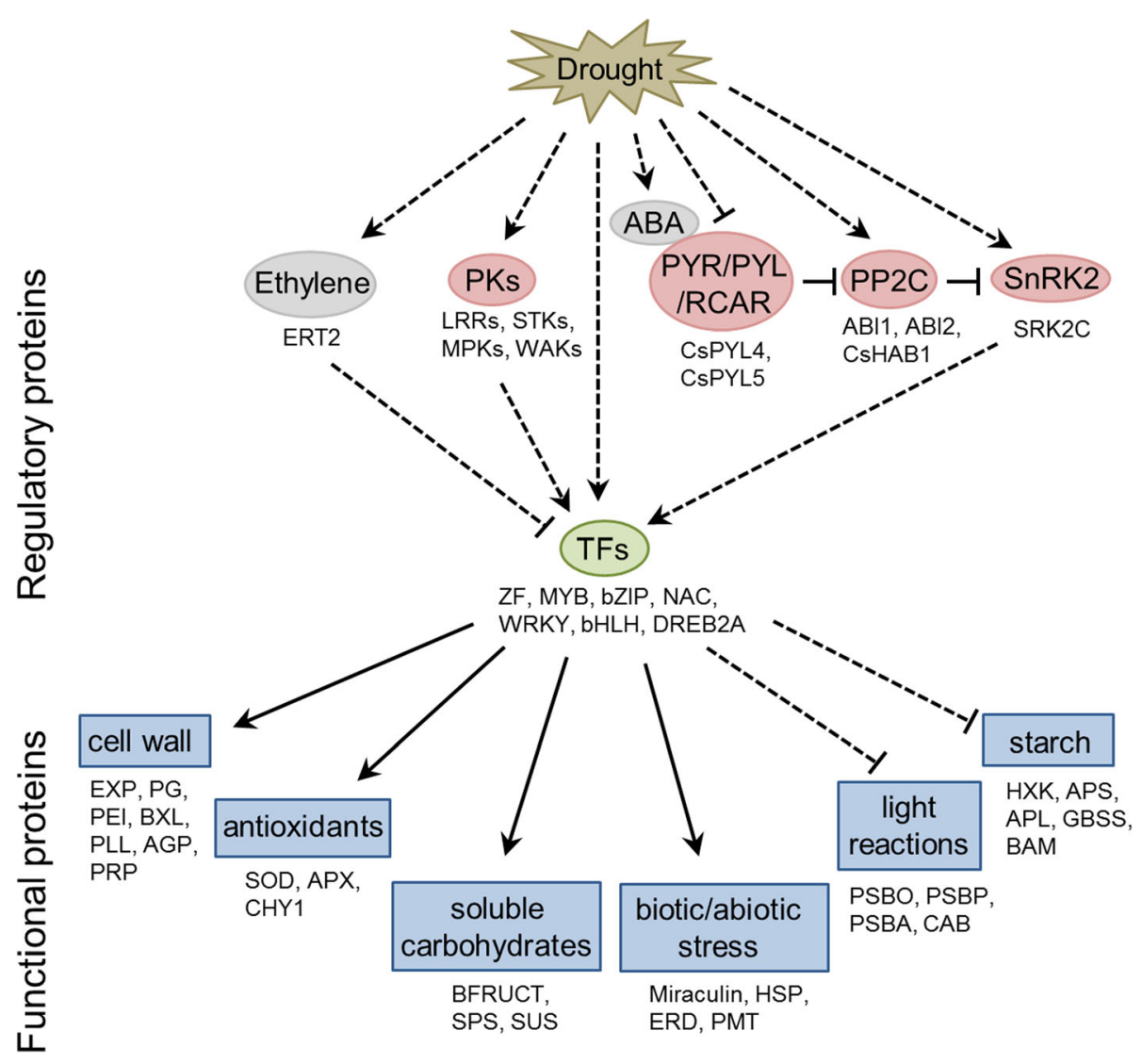

Fig. 3 A schematic model of the rootstock-induced transcriptional response associated with drought tolerance in leaves of sweet orange. Ovals represent proteins or hormones and squares represent processes. Representative proteins are shown below the corresponding ovals and squares. Dotted lines represent indirect connections and solid lines represent direct connections. Abbreviations: ABA: abscisic acid; ABI1: ABA-insensitive 1; ABI2: ABA-insensitive 2; AGP: arabinogalactan protein; APL, ADP-glucose pyrophosphorylase large subunit; APS: ADP-glucose pyrophosphorylase; APX: ascorbate peroxidase; BAM: beta-amylase; BFRUCT: beta-fructosidase; bHLH: basic helix-loop-helix motif; BXL: $\beta$-xylosidase; bZIP: basic region/leucine zipper motif; CAB: chlorophyll a/b binding protein; CHY1: beta-carotene hydroxylase 1; CSHAB1: Citrus sinensis hypersensitive to ABA 1; CSPYL4: Citrus sinensis pyrabactin resistance 1-like 4; CsPYL5: Citrus sinensis pyrabactin resistance 1-like 5; DREB2A: dehydration-responsive element binding protein 2A; ERD: early responsive to dehydration; ERT2: ethylene-responsive nuclear protein 2; EXP: expansin; HSP: heat shock protein; GBSS: granule bound starch synthase; HXK: hexokinase; LRRs: leucine rich repeats; MPKs: mitogen-activated kinases; MYB: myeloblastosis; NAC: NAM/ATAF/CUC; PEl: pectinesterase inhibitor; PG: polygalacturonase; PKs: protein kinases; PLL: pectin lyase-like; PMT: putrescine N-methyltransferase; PP2C: protein phosphatase type 2C; PRP: proline-rich protein; PSBA: photosystem II reaction center protein D1; PSBO: photosystem II subunit O; PSBP: photosystem II subunit P; PYR/PYL/RCAR: pyrabactin resistance 1/PYR1-like/regulatory components of ABA receptor; SnRK2: SNF1- related protein kinase 2; SOD: superoxide dismutase; SPS: sucrose phosphate synthase; SRK2C: SNF1-related protein kinase 2C; STKs: Serine/Threonine-protein kinases; SUS: sucrose synthase; TFs: transcription factors; WAKs: wall-associated kinases; WRKY: tryptophanarginine-lysine-tyrosine domain; ZF: zinc finger

\section{Sequence analysis}

The $101 \mathrm{bp}$ reads were collected and the sequences were mapped in the Citrus sinensis reference genome available in https://phytozome.jgi.doe.gov/pz/portal.html [53], using software TopHat. A quantitative assessment of the transcripts was used to calculate the levels of differential expression between control and drought treatments and significance levels using the Cuffdiff software, according to the procedures described by Coqueiro et al. [54]. The differentially expressed $(P \leq 0.001$, fold-change $\geq+2$ and $\leq-2)$ transcripts were recorded and automatically categorized using GO (Gene Ontology - http://www.blast2go.com/ b2ghome). The functions of the identified genes were evaluated by comparing with the A. thaliana database (https://arabidopsis.org). MapMan software (https:// mapman.gabipd.org) was also used as a tool for visualizing the functional classes significantly affected by drought treatment under diagrams of metabolic processes or other routes.

Expression analysis by quantitative real-time PCR (qPCR) Total RNA isolation and cDNA synthesis were performed as described previously [22]. Reverse transcription (RT) was performed using the RETROscript kit (Ambion, Austin, USA). Reactions were performed on a Stratagene $\mathrm{Mx}$ 3005P (Agilent Technologies) thermocycler containing the 
MxPro-Mx 3005P software, using the Maxima ${ }^{\mathrm{m}}$ SYBR Green/ROX qPCR Master Mix kit (Thermo Scientific). Genes used as endogenous controls (reference genes) were glyceraldehyde-3-phosphate dehydrogenase C2 (GAPC2) and ubiquitin-protein ligase (UPL) [55]. Primer sequences are detailed in Additional file 8: Table S7. Reactions were carried out in triplicates, in a volume of $22 \mu \mathrm{L}$, containing $100 \mathrm{ng}$ of cDNA, $1 \mu \mathrm{L}$ of each specific primer, $10 \mu \mathrm{mol} . \mathrm{L}^{-1}$ and $11 \mu \mathrm{L}$ of Maxima ${ }^{\circ}$ SYBR Green/ROX qPCR Master Mix (2X) (Fermentas, Maryland, USA). The amplification reactions were performed under the following conditions: (1) pretreatment at $50{ }^{\circ} \mathrm{C}$ for $2 \mathrm{~min}$, (2) activation of Taq DNA polymerase at $95^{\circ} \mathrm{C}$ for $10 \mathrm{~min}$, (3) denaturation at $95^{\circ} \mathrm{C}$ for $15 \mathrm{~s}$, (4) annealing at $60^{\circ} \mathrm{C}$ for $30 \mathrm{~s}$, (5) extension at $60^{\circ} \mathrm{C}$ for $1 \mathrm{~min}$. The steps $3-5$ were repeated for $30 \mathrm{cy}-$ cles. To test the specificity of the primers, the products were analyzed by dissociation curve. For quantification of the expression, the $2^{-\Delta \Delta \mathrm{Ct}}$ method [56] was used, considering the mean of the $\mathrm{Ct}$ values of the three replicates. Pearson correlations were calculated to compare the levels of gene expression measured by RNA-Seq and qPCR. Student's $t$ test was used to compare the gene expression levels between sweet orange plants grafted on 'Rangpur' lime and 'Flying Dragon' trifoliate.

\section{Additional files}

\section{Additional file 1: Table S1. Throughput and quality of RNA-Seq data.} (DOCX $12 \mathrm{~kb}$ )

Additional file 2: Table S2-1. Differentially expressed genes that were upregulated in leaves of drought-stressed sweet orange (Citrus sinensis) grafted on 'Rangpur' lime. (XLSX $71 \mathrm{~kb}$ )

Additional file 3: Table S2-2. Differentially expressed genes that were downregulated in leaves of drought-stressed sweet orange (Citrus sinensis) grafted on 'Rangpur' lime. (XLSX $50 \mathrm{~kb}$ )

Additional file 4: Table S3. Differentially expressed genes related to metabolic pathways in leaves of drought-stressed sweet orange (Citrus sinensis) grafted on 'Rangpur' lime. (XLSX 19 kb)

Additional file 5: Table S4. Differentially expressed genes related to cellular response in leaves of sweet orange (Citrus sinensis) grafted on 'Rangpur' lime. (XLSX 13 kb)

Additional file 6: Table S5. Differentially expressed genes related to the hormonal signaling pathways in leaves of sweet orange (Citrus sinensis) grafted on 'Rangpur' lime. (XLSX $12 \mathrm{~kb}$ )

Additional file 7: Table S6. Differentially expressed genes related to transcription factors and protein kinases in leaves of sweet orange (Citrus sinensis) grafted on 'Rangpur' lime. (XLSX 23 kb)

Additional file 8: Table S7. Primer sequences used for validation in qPCR. (XLSX $12 \mathrm{~kb}$ )

\section{Abbreviations}

ABA: Abscisic acid; $A B F$ : ABRE-binding factor; $A B$ 11: $A B A$-insensitive 1; $A B I 2$ : $A B A$ insensitive 2; ABRE: ABA-responsive element; $A D H 1$ : Alcohol dehydrogenase 1; AGP1: Arabinogalactan protein 1; AP2/ERF: APETALA2/ethylene responsive factor; APL: ADP-glucose pyrophosphorylase large subunit; APS: ADP-glucose pyrophosphorylase; APX: Ascorbate peroxidase; AREB2: ABRE-binding protein 2" BAM3: Beta-amylase 3; BEE 3-LIKE: Brassinosteroid enhanced expression 3-Like; BFRUCT3: Beta-fructosidase 3; bHLH: Basic helix-loop-helix motif;

BR: Brassinosteroid; BXL1: $\beta$-xylosidase 1; bZIP: Basic region/leucine zipper motif;
CAB: Chlorophyll a/b binding protein; CAT: Catalase; CESA: Cellulose synthase; CHY1: Beta-carotene hydroxylase 1; COR15A: Cold-related 15A; COR47: Coldrelated 47; CTR1: Constitutive triple response 1; DEGs: Differentially expressed genes; DREB1AVCBF3: Dehydration-responsive element binding protein 1A/Crepeat (CRT) binding factor 3; DREB2A: Dehydration-responsive element binding protein 2A; ERD: Early responsive to dehydration; ERT2: Ethylene-responsive nuclear protein 2; EST: Expressed sequence tag; EXLB1: Expansin-like B1; EXP: Expansin; FT: Flowering locus T; GA: Gibberellic acid; GAP2C: Glyceraldehyde3-phosphate dehydrogenase C2; GAP3C: Glyceraldehyde-3-phosphate dehydrogenase C3; GBSS1: Granule bound starch synthase 1; GGT: Glycogenin glucosyltransferase; GO: Gene ontology; HAB1: Hypersensitive to ABA 1; HSP: Heat shock protein; HVA22: Hordeum vulgare abscisic acid-induced protein 22; HXK2: Hexokinase 2; IAA: Indole-3-acetic acid; JA: Jasmonic acid; LEA: Late embryogenesis abundant; LOX2: Lipoxygenase 2; LRR: Leucine rich repeat; MAP: Mitogen-activated protein; MARD1: Mediator of ABA-regulated dormancy 1; MEKK1: Mitogen-activated kinase kinase; MPK: Mitogen-activated kinase; MPK6: MAP kinase 6; MYB: Myeloblastosis; NAC: NAM/ATAF/CUC;

PEG: Polyethylene glycol; PEI 54-like: Pectinesterase inhibitor 54-like; PEl 6like: Pectinesterase inhibitor 6-like; PEP2Cs: Protein phosphatases type 2C. PEPCK: Phosphoenol pyruvate carboxykinase; PG: Polygalacturonase; PKs: Protein kinases; PLL1: Pectin lyase-1 like; PMT: Putrescine N-methyltransferase; POD: Peroxidase; PRP4: Proline-rich protein 4; PSBA: Photosystem II reaction center protein D1; PSBO: Photosystem II subunit O; PSBP: Photosystem II subunit P; PYL: PYR1-like; PYR: Pyrabactin resistance 1; qPCR: Quantitative real-time PCR; RCAR: Regulatory components of ABA receptor; $\mathrm{RCI} 2$ : Rare-cold-inducible 2; RD29A: Responsive to dehydration 29A; ROS: Reactive oxygen species; RPS13A: Small subunit ribosomal protein S13A; RWC ${ }^{\text {TLP }}$ : Relative water content at turgor loss point; SnRK2: SNF1-Related protein kinase 2; SOD: Superoxide dismutase; SPS1F: Sucrose phosphate synthase 1F; SRK2C: SNF1-Related protein kinase 2C; STK: Serine/Threonine-protein kinase; SUS: Sucrose synthase; T6P: Trehalose-6-phosphate; TCA: Tricarboxylic acid; TFs: Transcription factors; TIR1: Transport inhibitor response 1; TPS: Trehalose-6-phosphate synthase; UPL: Ubiquitin-protein ligase; WAK: Wall-associated kinase; WAKL: WAK-like; WRKY: Tryptophan-arginine-lysine-tyrosine domain; WUE: Water use efficiency; ZF: Zinc finger

\section{Acknowledgements}

Not applicable.

\section{Funding}

This work was supported by research grants from CNPq (Process \# 478733/ 2013-5) and Instituto Nacional de Ciência e Tecnologia (INCT) de Genômica para Melhoramento de Citros (CNPq Process \# 465440/2014-2 and FAPESP Process \# 2008/2014/50880-0). LPG was recipient of a Ph.D. scholarship by CAPES Foundation. MAT, MAM, WSSF and MGCC are CNPq Research Fellows. The funders had no role in study design, data collection and analysis, decision to publish, or preparation of the manuscript. The funds provided were used to conduct all the molecular analysis performed in the present study.

\section{Availability of data and materials}

All data generated or analysed during this study are included in this published article and its supplementary information files. Raw transcriptomic data sets are available through the NCBI BioProject PRJNA513165 in https:// www.ncbi.nlm.nih.gov/sra/PRJNA513165.

\section{Authors' contributions}

LPG and MGCC conceived and designed the experiments. LPG performed the experiment. LPG, RLBC, MAT and MGCC analyzed the data. MAM, WSSF and MGCC supported the project. LPG drafted the manuscript. LPG, RLBC, MAT, MAM, WSSF and MGCC polished the manuscript. All authors read and approved the final manuscript.

Ethics approval and consent to participate

Not applicable.

\section{Consent for publication}

Not applicable.

\section{Competing interests}

The authors declare that they have no competing interests. 


\section{Publisher's Note}

Springer Nature remains neutral with regard to jurisdictional claims in published maps and institutional affiliations.

\section{Author details}

'Centro de Biotecnologia e Genética, Departamento de Ciências Biológicas, Universidade Estadual de Santa Cruz, Ilhéus, BA 45662-900, Brazil. ${ }^{2}$ Centro APTA Citros Sylvio Moreira, Instituto Agronômico, Cordeirópolis, SP 13490-970, Brazil. ${ }^{3}$ Embrapa Mandioca e Fruticultura, Cruz das Almas, BA 44380-000, Brazil.

\section{Received: 20 August 2018 Accepted: 24 January 2019} Published online: 06 February 2019

\section{References}

1. Faostat (2017) FAOSTAT online database. Food and Agriculture Organization of the United Nations. http://www.fao.org/faostat/en/\#data>.

2. Sentelhas PC. Agrometeorologia dos citros. In: Mattos Junior D, Negri JR, Pio RM, Pompeu Junior J, editors. Citros. Campinas: Instituto Agronômico e Fundag; 2005. p. 317-44.

3. Salekdeh GH, Reynolds M, Bennett J, Boyer J. Conceptual framework for drought phenotyping during molecular breeding. Trends Plant Sci. 2009;14: 488-96

4. Chaves MM, Oliveira MM. Mechanisms underlying plant resilience to water deficits: prospects for water-saving agriculture. J Exp Bot. 2004;55:2365-84.

5. García-Sánchez F, Syvertsen JP, Gimeno V, Botía P, Pérez-Pérez JG. Responses to flooding and drought stress by two citrus rootstocks seedlings with different water-use efficiency. Physiol Plant. 2007;130:532-42.

6. Pérez-Pérez JG, Robles JM, Tovar JC, Botía P. Response to drought and salt stress of lemon 'Fino 49' under field conditions: water relations, osmotic adjustment and gas exchange. Sci Hortic. 2009;122:83-90.

7. Rodríguez-Gamir J, Primo-Millo E, Forner JB, Forner-Giner MA. Citrus rootstock responses to water stress. Sci Hortic. 2010;126:95-102.

8. Neves DM, Coelho-Filho MA, Bellete BS, Silva MFGF, Souza DT, Soares-Filho WS, Costa MGC, Gesteira AS. Comparative study of putative 9-cisepoxycarotenoid dioxygenase and abscisic acid accumulation in the responses of Sunki mandarin and Rangpur lime to water deficit. Mol Biol Rep. 2013;40:5339-49.

9. Pedroso FKJV, Prudente DA, Bueno ACR, Machado EC, Ribeiro RV. Drought tolerance in citrus trees is enhanced by rootstock-dependent changes in root growth and carbohydrate availability. Environ Exp Bot. 2014;101:26-35.

10. Gonzalez-Altozano P, Castel JR. Regulated deficit irrigation in "Clementina de Nules" citrus trees. II. Vegetative growth. J Hortic Sci Biotechnol. 2000;75: 388-92.

11. Pérez-Pérez JG, Romero P, Navarro JM, Botía P. Response of sweet orange cv 'Lane late' to deficit irrigation in two rootstocks. I: water relations, leaf gas exchange and vegetative growth. Irrig Sci. 2008;26:415-25.

12. Melgar JC, Dunlop JM, Syvertsen JP. Growth and physiological responses of the citrus rootstock Swingle citrumelo seedlings to partial rootzone droughting and deficit irrigation. J Agric Sci. 2010;148:593-602.

13. Savé R, Biel C, Domingo R, Ruiz-Sánchez MC, Torrecillas A. Some physiological and morphological characteristics of citrus plants for drought resistance. Plant Sci. 1995;110:167-72.

14. Barry GH, Castle WS, Davies FS. Rootstocks and plant water relations affect sugar accumulation of citrus fruit via osmotic adjustment. J Am Soc Hortic Sci. 2004;129:881-9.

15. Romero P, Navarro JM, Pérez-Pérez J, García-Sánchez F, Gómez-Gómez A, Porras I, Martinez V, Botía P. Deficit irrigation and rootstock: their effects on water relations, vegetative development, yield, fruit quality and mineral nutrition of Clemenules mandarin. Tree Physiol. 2006;26: 1537-48.

16. Cantuarias-Avilés T, Mourão Filho FAA, Stuchi ES, Silva SR, Espinoza-Nuñez E. Horticultural performance of 'Folha Murcha' sweet orange onto twelve rootstocks. Sci Hortic. 2011;129:259-65.

17. Bassanezi RB, Bergamin Filho A, Amorin L, Gimenes-Fernandes N, Gottwald TR, Bové JM. Spatial and temporal analyses of Citrus sudden death as a tool to generate hypotheses concerning its etiology. Phytopathology. 2003;93: 502-12

18. Medina CL, Machado EC, Pinto JM. Photosynthesis of 'Valencia' orange tree grafted on four rootstocks and submitted to water deficit. Bragantia. 1998; 57:1-14.
19. Magalhães Filho JR, Amaral LR, Machado DFSP, Medina CL, Machado EC. Water deficit, gas exchange and root growth in 'Valencia' orange tree budded on two rootstocks. Bragantia. 2008;67:75-82.

20. Boscariol-Camargo RL, Berger IJ, Souza AA, Amaral AM, Carlos EF, Freitas-Astúa J, Takita MA, Targon MLPN, Medina CL, Reis MS, Machado MA. In silico analysis of ESTs from roots of Rangpur lime (Citrus limonia Osbeck) under water stress. Genet Mol Biol. 2007;30:906-16.

21. Gimeno J, Gadea J, Forment J, Pérez-Valle J, Santiago J, Martínez-Godoy MA, Yenush L, Bellés JM, Brumós J, Colmenero-Flores JM, Talón M, Serrano R. Shared and novel molecular responses of mandarin to drought. Plant Mol Biol. 2009;70: 403-20.

22. Gonçalves LP, Alves TFO, Martins CP, Sousa AO, Santos IC, Pirovani CP, Almeida AF, Filho MAC, Gesteira AS, Filho WSS, Girardi EA, Costa MGC. Rootstock-induced physiological and biochemical mechanisms of drought tolerance in sweet orange. Acta Physiol Plant. 2016;38:1-12.

23. Corso M, Vannozzi A, Maza E, Vitulo N, Meggio F, Pitacco A, Telatin A, D'Angelo M, Feltrin E, Negri AS, et al. Comprehensive transcript profiling of two grapevine rootstock genotypes contrasting in drought susceptibility links the phenylpropanoid pathway to enhanced tolerance. J Exp Bot. 2015;66:5739-52.

24. Pagliarani C, Vitali M, Ferrero M, Vitulo N, Incarbone M, Lovisolo C, Valle G, Schubert A. The accumulation of miRNAs differentially modulated by drought stress is affected by grafting in grapevine. Plant Physiol. 2017;173: 2180-95.

25. Li C, Li Y, Bai L, Zhang T, He C, Yan Y, Yu X. Grafting-responsive miRNAs in cucumber 883 and pumpkin seedlings identified by high-throughput sequencing at whole genome level. Physiol Plant. 2014;151:406-22.

26. Thimm O, Bläsing O, Gibon Y, Nagel A, Meyer S, Krüger P, Selbig J, Müller LA, Rhee SY, Stitt M. MAPMAN: a user-driven tool to display genomics data sets onto diagrams of metabolic pathways and other biological processes. Plant J. 2004;37: 914-39.

27. Xu Q, Chen LL, Ruan X, Chen D, Zhu A, Chen C, et al. The draft genome of sweet orange (Citrus sinensis). Nat Genet. 2013;45:59-66.

28. Gall HL, Philippe F, Domon JM, Gillet F, Pelloux J, Rayon C. Cell wall metabolism in response to abiotic stress. Plants. 2015;4:112-66.

29. Lamport DT, Kieliszewski MJ, Showalter AM. Salt stress upregulates periplasmic arabinogalactan proteins: using salt stress to analyse AGP function. New Phytol. 2006;169:479-92.

30. Harb A, Krishnan A, Ambavaram MM, Pereira A. Molecular and physiological analysis of drought stress in Arabidopsis reveals early responses leading to acclimation in plant growth. Plant Physiol. 2010;154:1254-71.

31. An SH, Sohn KH, Choi HW, Hwang IS, Lee SC, Hwang BK. Pepper pectin methylesterase inhibitor protein CaPMEl1 is required for antifungal activity, basal disease resistance and abiotic stress tolerance. Planta. 2008;228:61-78.

32. Baud S, Vaultier M-N, Rochat C. Structure and expression profile of the sucrose synthase multigene family in Arabidopsis. J Exp Bot. 2004;55: 397-409.

33. Haouazine-Takvorian N, Tymowska-Lalanne Z, Takvorian A, Tregear J, Lejeune $B$, Lecharny A, Kreis M. Characterization of two members of the Arabidopsis thaliana gene family, At $\beta$ fruct3 and At $\beta$ fruct4, coding for vacuolar invertases. Gene. 1997;197:239-51.

34. Park JY, Canam T, Kang KY, et al. Over-expression of an arabidopsis family a sucrose phosphate synthase (SPS) gene alters plant growth and fibre development. Transgenic Res. 2008;17:181.

35. Santana-Vieira DDS, et al. Survival strategies of citrus rootstocks subjected to drought. Sci Rep. 2016;6:38775.

36. Valluru R, Van Den Ende W. Myo-inositol and beyond - emerging networks under stress. Plant Sci. 2011;181:387-400.

37. Giese JO, Herbers K, Hoffmann M, Klosgen RB, Sonnewald U. Isolation and functional characterization of a novel plastidic hexokinase from Nicotiana tabacum. FEBS Lett. 2005;579:827-31.

38. Galme's J, Abadía A, Cifre J, Medrano H, Flexas J. Photoprotection processes under water stress and recovery in Mediterranean plants with different growth forms and leaf habits. Physiol Plant. 2007;130:495-510.

39. Teuber M, Azemi ME, Namjoyan F, Meier AC, Wodak A, Brandt W, Dräger B. Putrescine N-methyltransferases - a structure-function analysis. Plant Mol Biol. 2007:63:787-801.

40. Yer EN, Baloglu MC, Ziplar UT, Ayan S, Unver T. Drought-responsive Hsp70 gene analysis in Populus at genome-wide level. Plant Mol Biol Rep. 2016;34: 483-500. 
41. Romero P, Lafuente MT, Rodrigo MJ. The Citrus ABA signalosome: identification and transcriptional regulation during sweet orange fruit ripening and leaf dehydration. J Exp Bot. 2012;63:4931-45.

42. Hou XJ, Li SB, Liu SR, Hu CG, Zhang JZ. Genome-wide classification and evolutionary and expression analyses of citrus MYB transcription factor families in sweet orange. PLoS One. 2014;9:e112375.

43. Yan Y, Shen L, Chen Y, Bao S, Thong Z, Yu H. A MYB-domain protein EFM mediates flowering responses to environmental cues in Arabidopsis. Dev Cell. 2014;30:437-48.

44. Huang X-S, Liu J-H, Chen X-J. Overexpression of PtrABF gene, a bZIP transcription factor isolated from Poncirus trifoliata, enhances dehydration and drought tolerance in tobacco via scavenging ROS and modulating expression of stress-responsive genes. BMC Plant Biol. 2010;10:230.

45. Matsukura S, Mizoi J, Yoshida T, Todaka D, Ito Y, Maruyama K, Shinozaki K, Yamaguchi-Shinozaki K. Comprehensive analysis of rice DREB2-type genes that encode transcription factors involved in the expression of abiotic stress-responsive genes. Mol Gen Genomics. 2010;283:185-96.

46. Friedrichsen DM, Nemhauser J, Muramitsu T, Maloof JN, Alonso J, Ecker JR, et al. Three redundant brassinosteroid early response genes encode putative bHLH transcription factors required for normal growth. Genetics. 2002;162:1445-56.

47. Noh SA, Choi Yl, Cho JS, Lee H. The poplar basic helix-loop-helix transcription factor BEE3-like gene affects biomass production by enhancing proliferation of xylem cells in poplar. Biochem Biophys Res Commun. 2015; 462:64-70.

48. Wu Y, Deng Z, Lai J, Zhang Y, Yang C, Yin B, Zhao Q, Zhang L, Li Y, Yang C. Dual function of Arabidopsis ATAF1 in abiotic and biotic stress responses. Cell Res. 2009;19:1279-90.

49. Gong X-Q, Hu J-B, Liu J-H. Cloning and characterization of FcWRKY40, a WRKY transcription factor from Fortunella crassifolia linked to oxidative stress tolerance. Plant Cell Tissue Organ Cult. 2014;119:197-210.

50. Umezawa T, Yoshida R, Maruyama K, Yamaguchi-Shinozaki K, Shinozaki K. SRK2C, a SNF1-related protein kinase 2, improves drought tolerance by controlling stress-responsive gene expression in Arabidopsis thaliana. Proc Natl Acad Sci U S A. 2004;101:17306-11

51. Nadarajah K, Sidek HM. The green MAPKs. Asian J Plant Sci. 2010;9:1-10.

52. Kohorn BD. Cell wall-associated kinases and pectin perception. J Exp Bot. 2015;67:489-94.

53. Wu GA, Prochnik S, Jenkins J, Salse J, Hellsten U, Murat F, et al. Sequencing of diverse mandarin, pummelo and orange genomes reveals complex history of admixture during citrus domestication. Nat Biotechnol. 2014;32: 656-62.

54. Coqueiro DSO, Souza AA, Takita MA, Rodrigues CM, Kishi LT, Machado MA. Transcriptional profile of sweet orange in response to chitosan and salicylic acid. BMC Genomics. 2015;16:288

55. Mafra V, Kubo KS, Alves-Ferreira M, Ribeiro-Alves M, Stuart RM, Boava LP, et al. Reference genes for accurate transcript normalization in citrus genotypes under different experimental conditions. PLoS One. 2012:7:e31263.

56. Livak KJ, Schmittgen TD. Analysis of relative gene expression data using real-time quantitative PCR and the $2^{-\Delta \Delta C T}$ method. Method. 2001;25:402-8.

Ready to submit your research? Choose BMC and benefit from:

- fast, convenient online submission

- thorough peer review by experienced researchers in your field

- rapid publication on acceptance

- support for research data, including large and complex data types

- gold Open Access which fosters wider collaboration and increased citations

- maximum visibility for your research: over $100 \mathrm{M}$ website views per year

At $\mathrm{BMC}$, research is always in progress.

Learn more biomedcentral.com/submissions 